\title{
IMPLICAÇÕES MÉDICO-ESPORTIVAS DAS FRATURAS DO PLANALTO TIBIAL
}

Rubens Lombardi Rodrigues*

RESUMO

\begin{abstract}
Através do estudo de 76 casos de fraturas do planalto tibial coletados no Departamento de Ortopedia e Traumatologia da Facuidade de Ciências Médicas da Santa Casa de Säo Paulo verificou-se que $34,20 \%$ das traturas supracitadas eram laterais mistas, e que outros $25 \%$ destas fraturas eram bituberositárias
\end{abstract}

\section{INTRODUÇÃO}

As fraturas do planalto tibial se constituem em preocupação constante para o traumatologista. Em 1929 esta fratura foi denominada por Cotton e Berg (2) de "bumper fracture" porque na maioria das vezes, ela era causada pela batida do para-choque do automóvel, na face lateral o joeIho estendido de um pedestre.

Naves (7) em 1952 cita as fraturas do planalto lateral da tíbia nos acidentes de esqui, motociclismo e no automobilismo, mostrando ser esta lesão, pouco frequente na prática esportiva, porém possivel de ocorrer, devendo o traumatologista especializado em Medicina Esportiva, estar atento e atualizado, para o seu tratamento.

Na mesma época Wilson e Jacobs (11) usaram a superfície articular da rótula para substituir a superfície articular lesada do planalto lateral da tíbia.

Böhler (1) refere-se a uma determinada "atlopatia" do planalto tibial, com o joelho em flexão e que considera como típica do motociclista. mistas; predominando portanto as fraturas mistas sobre os demais tipos, embora as fraturas laterais com afundamento também tivessem local de destaque, ainda que em número inferior as já acima citadas, com $15,78 \%$.

Hohl e Luck (4), após exaustiva recisāo de 227 casos de fraturas do planalto tibial, com 2 a 13 anos de evolução indicam tratamento conservador nos seguintes casos: fraturas sem desvio; fraturas com afundamento menor que $1 \mathrm{~cm}$ e afastamento menor que $0,5 \mathrm{~cm}$.

Consideram que a movimentaçāo ativa precoce é o recurso mais importante para se obter ótimo resultado nas fraturas dos côndilos da tíbia.

Dupart e Ficat (3), sob a denominaçāo de "Fraturas articulares da extremidade superior da tibia" estudam todas as fraturas do bloco esponjoso-metafisário, determinando para cada tipo de lesão uma modalidade de tratamento.

O mesmo ocorre com Merle D'Aubigne e Mazas (5), que acompanharam 60 casos. Propõe uma classificação simples segundo o tipo e a sede da lesão.

Oliveiras (9) em seu livro "Lesiones Deportivas y Profesionales" refere-se a esse tipo de fratura e aconselha o tratamento sob tração esquelética para os casos em que haja desvios e posteriormente o uso do gesso cruro-podálico.

Professor Assistente Doutor da disciplina Socorros de Urgência, da EEF-USP 
Mourges e Chaix (6) revisaram 125 casos de fraturas do planalto tibial, tratados durante 7 anos. Tração contínua com exercícios ativos foram usados em 72 casos e é por eles considerado o meIhor tratamento.

O'Donoghue (8) cita este tipo de fratura em jovens atletas considerando-a como pouco frequente, em contrapartida comenta sobre a possibilidade de lesão ligamentar junto a articulação do joelho. Lembra ainda a necessidade de exame radiológico, para ser excluida a possibilidade de fratura.

Schulak e Gunn (10) fazem um estudo comparativo de 13 trabalhos, e que sāo confrontados entre si. Referem que as lesōes meniscais sāo encontradas em $50 \%$ dos casos. As lesōes ligamentares são encontradas entre 10 e $30 \%$ dos casos. Afirmam a necessidade de reduçāo das fraturas com desvios. Redução cirúrgica e fixaçāo interna com enxertos ósseos são sugeridas nos afastamentos e afundamentos. Mobilização precoce da articulação do joelho afetado é importante em todas as fraturas.

A reabilitaçāo do quadríceps femoral necessita ser vigorosa. O suporte de carga será impossivel, pelo menos, durante 3 meses.

\section{OBJETIVO}

O objetivo deste trabalho é divulgar a classificação das fraturas do planalto tibial, seguindo-se a conceituaçāo de Duparc e Ficat elaborada em 1960, tanto no que se refere à localização da mesma na superfície articular do bloco epifisometafisário da extremidade superior da tíbia, quanto aos desvios que os fragmentos ósseos possam apresentar.

\section{CONCEITOS}

3.1. Quanto a localização, temos 3 tipos de fraturas do planalto tibial:

\subsubsection{Fratura da tuberosidade lateral} Aqui a fratura situa-se na superfície articular no bloco epifiso metafisário lateral da tíbia (Fig. 1).

\subsubsection{Fratura da tuberosidade medial} Aqui a fratura situa-se na superfície articular no bloco epifiso metafisário medial da tíbia (Fig. 2).

\subsubsection{Fratura bituberositária}

Aqui a fratura situa-se na superfície articular e no bloco epifiso metafisário lateral e medial da tíbia (Fig. 3).

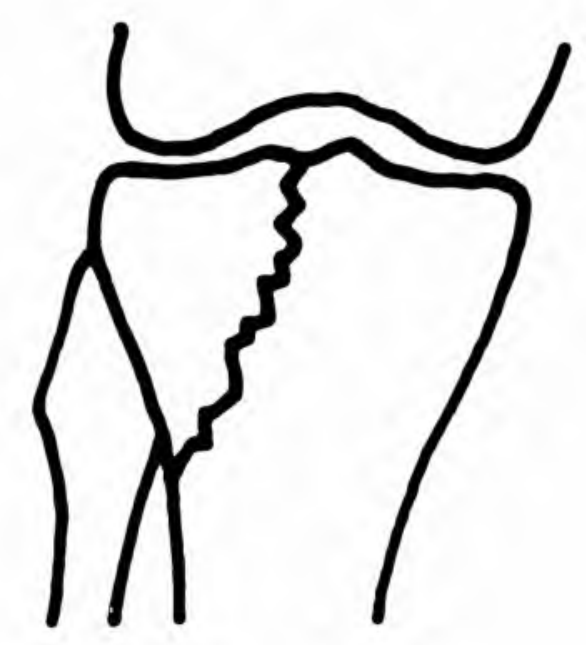

Fig. 1 Fratura da tuberosidade lateral

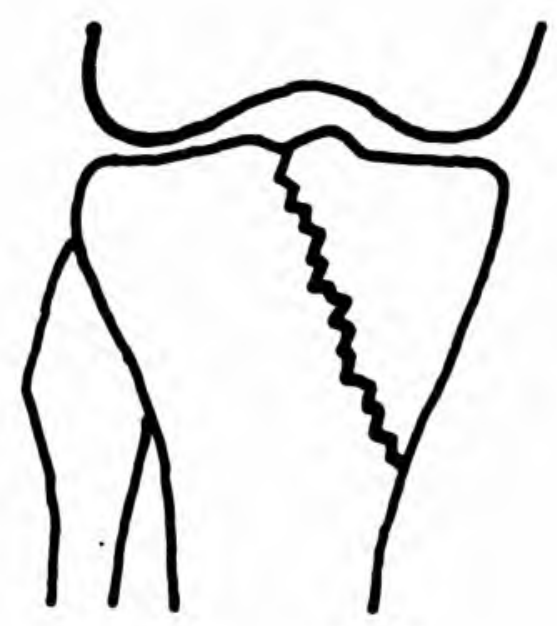

Fig. 2 Fratura da tuberosidade medial

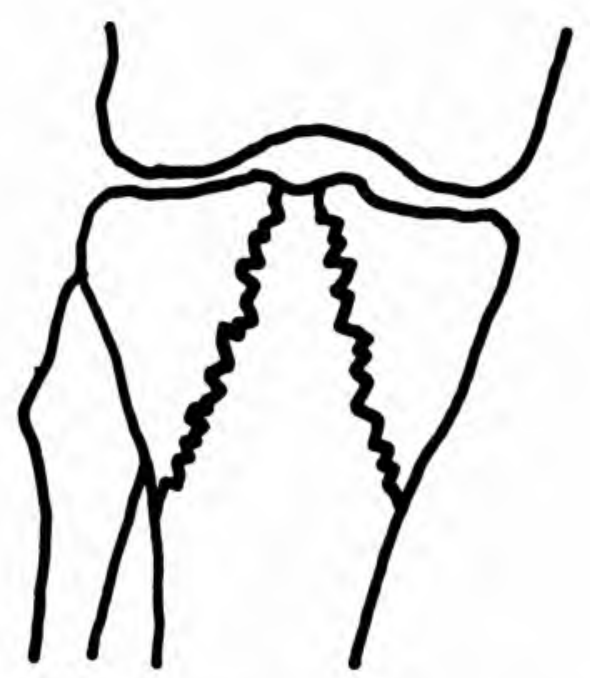

Fig. 3 Fratura bituberositária 
3.2. Quanto aos desvios, temos 4 tipos de fraturas do planalto tibial.

\subsubsection{Com afundamento}

A fratura é com afundamento quando o ângulo formado entre a linha perpendicular ao maior eixo diafisário da tíbia e outra que tangencie a superfície articular do fragmento desviado, for maior que cinco graus, segundo Anger, tornando-a cirúrgica (Fig. 4).

\subsubsection{Com afastamento}

A fratura é com afastamento, quando a separação entre o fragmento fraturado e o resto do osso for maior que meio centímetro, tornando-a cirúrgica (Fig. 5).

\subsubsection{Mistas}

São aquelas fraturas que apresentam afundamento e afastamento do fragmento ósseo em relação ao bloco epifiso-metafisário da extremidade superior da tíbia (Fig. 6).

\subsubsection{Sem desvios (bituberositárias)}

São aquelas que não apresentam afundamento ou afastamento dos fragmentos ósseos (Fig. 7).

\section{COLETA DE DADOS}

Nossas observações foram baseadas num levantamento de dados de 76 pacientes tratados

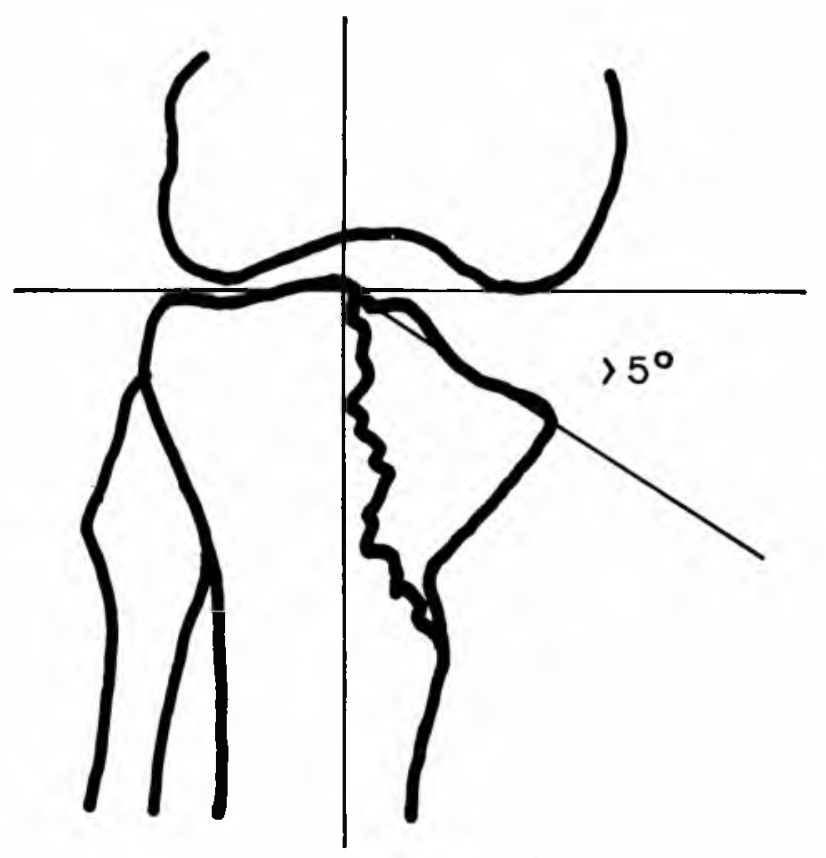

Fig. 4 Fratura com afundamento no Pavilhão Fernandinho Simonsen, do Departamento de Ortopedia e Traumatologia da Faculdade de Ciências Médicas da Santa Casa de São Paulo.

Destes 76 pacientes, 55 pertenciam ao sexo masculino e 21 ao sexo feminino.

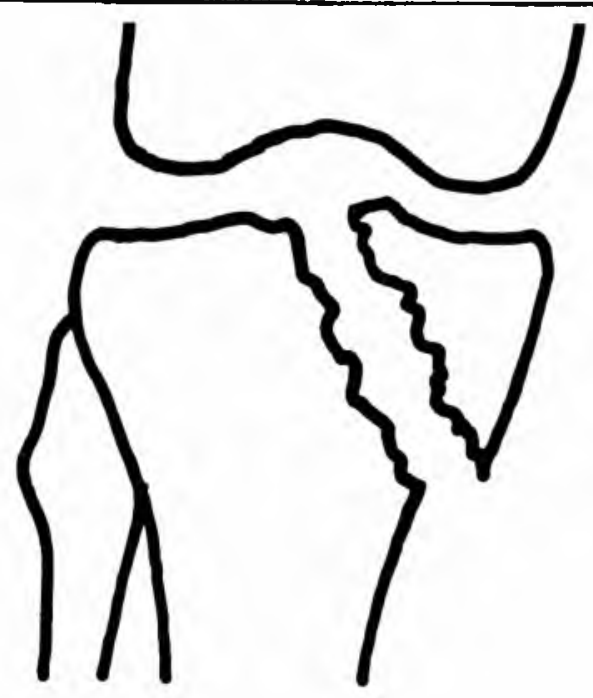

Fig. 5 Fratura com afastamento

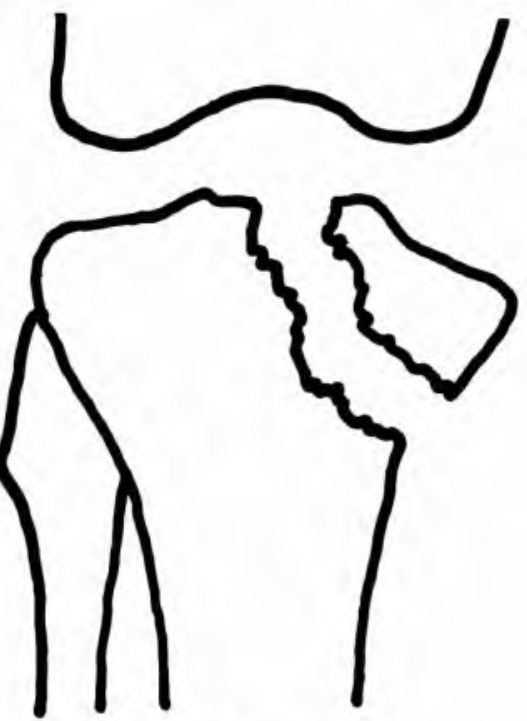

Fig. 6 Fratura mista

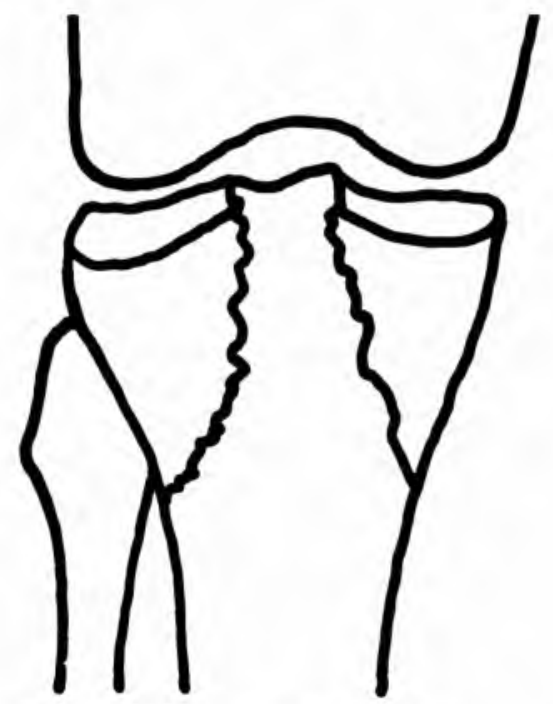

Fig. 7 Fratura sem desvios 
Tabela 1 Incidência da tuberosidade da tibia atingida nas fraturas do planalto tibial

\begin{tabular}{l|c|c}
\hline Tuberosidade Atingida & Pacientes & Porcentagem \\
\hline Lateral & 47 & 61,84 \\
\hline Medial & 8 & 10,53 \\
\hline Bituberositária & 21 & 27,63 \\
\hline Total & 76 & 100,00 \\
\hline
\end{tabular}

\section{ANÁLISE E DISCUSSÃO DOS RE- SULTADOS}

Os 76 pacientes envolvidos neste trabalho foram todos submetidos a cirurgia, com reduçāo cruenta e osteossintese da fratura.

Observou-se nestes pacientes que tanto o joelho direito como o joelho esquerdo, foram igualmente lesados.

Em relação à tuberosidade mais atingida observou-se grande predominância da lesāo na tuberosidade lateral da tíbia por causa da sua posição mais susceptivel de ser atingida, em concordância com os autores citados neste trabalho.

A Tabela 1 nos dá uma visāo ampla da ocorrência.

Em relação aos desvios dos fragrimentos ósseos observou-se que desvio misto, isto é, o afundamento associado ao afastamento dos fragmentos ósseos, predominou neste tipo de fratura, em relação àquelas que apresentavam somente afundamento ou afastamento, isoladamente ( $\mathrm{Ta}$ bela 2 ).
Analisou-se também os diversos tipos de fraturas associadas aos diferentes tipos de desvios dos fragmentos ósseos e foi possível constatar que a fratura do planalto lateral mista foi a predominante, acompanhada pela fratura bituberositária mista (Tabela 3).

Tabela 2 Incidência dos desvios dos fragmentos ósscos nas fraturas do planalto tibial.

\begin{tabular}{l|c|c}
\hline Desvios & Pacientes & Porcentagem \\
\hline Afundamento & 14 & 18,42 \\
\hline Afastamento & 16 & 21,05 \\
\hline Misto & 46 & 60,53 \\
\hline Total & 76 & 100,00 \\
\hline
\end{tabular}

Tabeia 3 Incidência das lesões associadas às fraturas do planalto tibial.

\begin{tabular}{l|c|c}
\hline Fratura & Pacientes & Porcentagem \\
\hline Lateral com afundamento & 12 & 15,79 \\
Lateral com afastamento & 9 & 11,84 \\
Lateral mista & 26 & 34,21 \\
\hline Medial com afundamento & 2 & 2,63 \\
Medial com afastamento & 5 & 6,58 \\
Medial mista & 1 & 1,32 \\
\hline Bituberositária com afundamento & 0 & 0,00 \\
Bituberositária com afastamento & 2 & 2,63 \\
Bituberositária mista & 19 & 100,00 \\
\hline Total & 76 & \\
\hline
\end{tabular}




\section{CONCLUSÕES}

1. As fraturas conceituadas neste trabalho como sendo as fraturas do côndilo lateral e com desvio misto foram as mais fre- quentes, alcançando a porcentagem de $34,21 \%$.

2. As fraturas bituberositárias mista ocupam a segunda posição com $25 \%$ de freqüência.

\section{ABSTRACT}

Through a study of 76 cases of fractures of the tibial plateau, observed at the Departament of Ortopedics and Traumatology of the "Faculdade de Ciencias Médicas da Santa Casa de São Paulo", it was verified that $34,20 \%$ of the above mentioned fractures were of the type mixed lateral, and that $25,00 \%$ of these fractu- res were of the type mixed bituberositary; the mixed fractures predominated over the other types but the lateral fractures with depression had a noticeable incidence corresponding although to a number smaller than other types, with $15,78 \%$.

\section{REFERÊNCIAS BIBLIOGRÁFICAS}

1. BÖHLER, L. Técnicas del tratamiento de las fracturas, 3.ed., Barcelona, Labor, 1954, p.1201-1224, v.2.

2. COTTON, F.J. \& BERG, R. "Fender fractures" of the tibia at the Knee. New England Journal. (201): 989-995, 1929.

3. DUPARC, J. \& FICAT, P. Fractures articulaires de l'extrémité supérieure du tibia. Rev. Chir. Orthop.46 (4): 309-486, 1960.

4. HOHL, M. \& LUCK, J.V. Fracture of the tibial condyle. J. Bone Jt. Surg. 38A (5): $1001-1018,1956$.

5. MERLE D'AUBIGNÉ, R. \& MAZAS, F Formes anatomiques et traitement des fractures de l'extrémité supérieure du tibia. Rev. Chir. Orthop. 46 (3): 290-318, 1960.
6. MOURGUES, G. DE \& CHAIX, D. Traitement des fractures des plateaux tibiaux. Rev. Chir. Orthop. 50 (1): 103-122, 1964.

7. NAVES, J. Medicina del deporte y accidentes deportivos. Barcelona, Salvat-Editores, 1952.

8. O'DONOGHUE, D.H. Treatment of injuries to athletes. Philadelphia, W.B. Saunders, 1970.

9. OLIVEIRAS, J.P Lesiones deportivas y profesionales. Barcelona, Teide, 1964.

10. SCHULAK, J.D. \& GUNN, D.R. Fractures of the tibial plateau: a review of the literature. Clin. Orthop. (109): 166-176, 1975.

11. WILSON, W.J. \& JACOBS, J.E. Patellar Graff for severely depressed comminuted fractures of the lateral tibial condyle. J. Bone Jt. Surg. 34A (2): 436 -442, 1952. 